\title{
Lipidic profile among rats submitted to total splenectomy isolated or combined with splenic autotransplant ${ }^{1}$
}

\author{
Perfil lipídico em ratos submetidos a esplenectomia total isolada ou combinada com \\ auto-implante esplênico
}

\author{
Fernanda Correia Simões², Ruy Garcia Marques ${ }^{3}$, Cristina Fajardo Diestel ${ }^{4}$, Carlos Eduardo Rodrigues Caetano ${ }^{5}$, Ana \\ Paula Gonçalves Dinis ${ }^{6}$, Nara Limeira Horst ${ }^{7}$, José Firmino Nogueira Neto ${ }^{8}$, Margareth Crisóstomo Portela ${ }^{9}$ \\ 1. Research performed at Laboratory of Experimental Surgery, Department of General Surgery, Post-graduation Program on Physiopathology \\ and Surgical Sciences - Rio de Janeiro State University, Rio de Janeiro, Brazil \\ 2. Post-graduate student, Dietitian - Rio de Janeiro State University, Brazil \\ 3. M.D., Ph.D., Associate Professor and Chairman of the Department of General Surgery -Rio de Janeiro State University, Brazil \\ 4. M.Sci., Dietitian; Pedro Ernesto University Hospital - Rio de Janeiro State University, Brazil \\ 5. Veterinary - Laboratory of Experimental Surgery - Rio de Janeiro State University, Brazil. \\ 6. Post-graduation student, Dietitian - Rio de Janeiro State University, Brazil \\ 7. M.Sci., Dietitian - Laboratory of Experimental Surgery - Rio de Janeiro State University, Brazil \\ 8. Lipids Laboratory - LabLip - Rio de Janeiro State University, Brazil \\ 9. Ph.D., Department of Health Administration and Planning - National School of Public Health - Oswaldo Cruz Foundation, Rio de \\ Janeiro, Brazil
}

\begin{abstract}
PURPOSE: To evaluate the alterations on plasmatic lipids levels among rats submitted to total splenectomy isolated or combined with splenic autotransplant receiving standard chow during the postoperative period. METHODS: Thirty Wistar rats were divided into three groups: control (C) - sham-operated, total splenectomy - isolated (TS) or combined with splenic autotransplantation (SA). Since the postoperative period, all animals received standard rat chow manipulated in accordance to the American Institute of Nutrition Rodents Diets (1993). The plasmatic levels of total cholesterol (TC), triglycerides (TG), high-density lipoprotein (HDL), low-density lipoprotein (LDL), very-low-density lipoprotein (VLDL), and glucose (GLUC) were analyzed before the surgical procedure and after 6 and 12 weeks.

RESULTS: All the animals presented significant increase of TG and VLDL levels. In relation to the other parameters there was no difference among the weeks 0 and 12 in the animals of group C. In TS group significant increase was observed in TC and GLUC levels during the experiment. In SA group TC, HDL, and GLUC levels remained unaffected while HDL levels increased. CONCLUSION: Our findings suggest that isolated total splenectomy alters lipids metabolism in rats fed with standard chow and splenic autotransplantation is effective in restoring its control.
\end{abstract}

Key words: Splenectomy. Transplantation. Lipid metabolism. Animal feed

\section{RESUMO}

OBJETIVO: Avaliar as alterações nos níveis de lipídios plasmáticos em ratos submetidos a esplenectomia total isolada ou combinada com auto-implante esplênico, recebendo dieta padrão no período pós-operatório. MÉTODOS: Trinta ratos Wistar foram distribuídos em três grupos: controle (C) - operação simulada, esplenectomia total isolada (ET) ou combinada com auto-implante esplênico (AE). A partir do período pós-operatório, todos os animais receberam ração padrão, manipulada segundo o American Institute of Nutrition (1993). Os níveis plasmáticos de colesterol total (CT), triglicerídeos (TG), lipoproteína de alta densidade (HDL), lipoproteína de baixa densidade (LDL), lipoproteína de muito baixa densidade (VLDL) e glicose (GLIC) foram analisados antes do procedimento e após 6 e 12 semanas.

RESULTADOS: Todos os animais apresentaram aumento de TG e VLDL. Em relação aos demais parâmetros, não ocorreu diferença entre as semanas 0 e 12 nos animais do grupo C. No grupo ET, observou-se aumento de CT e GLIC durante o experimento. No grupo AE, os níveis de CT, HDL e GLIC permaneceram inalterados enquanto os níveis de HDL se elevaram. CONCLUSÃO: Nossos achados sugerem que a esplenectomia total isolada altera o metabolismo lipídico em ratos alimentados com ração padrão e que o auto-implante esplênico é eficaz na restauração do seu controle.

Descritores: Esplenectomia. Transplante. Metabolismo dos lipídios. Alimentação animal. 


\section{Introduction}

The spleen is known to be one of the major organs of the mononuclear phagocytic system, acting as a biologic filter and playing an important role in immunity. It is also well-documented that splenectomy may result in serious hematological, immunological, and hemostaseological complications. ${ }^{1,2}$ Additionally, some authors verified that lipid metabolism suffers influence of the spleen, observing an increase on plasmatic levels of cholesterol after spleen removal in animals. ${ }^{3,4}$ In patients with splenomegaly due to myeloproliferative disorders or hereditary spherocytosis the plasmatic levels of cholesterol become reduced; however, after splenectomy plasma cholesterol and low-density lipoprotein significantly increase, reaching maximum levels. ${ }^{5}$ Significant increase in the plasmatic levels of triglycerides and decrease of the levels of HDL was observed in rats after total splenectomy, compared with sham-operated animals, all fed with standard chow. Even with the fact that those alterations have also been observed in the animals fed with diet with high lipids levels, they turned more evident in the splenectomized rats. ${ }^{6}$ Some authors try to explain such mechanism: Schmidt et al (1997) compared the spleen to a lipid reservoir, which rises in hyperplenism states. The splenic macrophages would accumulate great part of the fat through increase of the phagocytosis and consequent hypolipidemy. ${ }^{7}$ The immunological effect of the mononuclear phagocytic system against structures found in the lipoproteins HDL and LDL, resulting in its plasmatic purification, would be other possible explanation for the reduction of the plasmatic levels of lipids in the presence of the spleen. ${ }^{8}$ There is an evident relationship between dyslipidemy and the occurrence of vascular disease, especially atherosclerosis that is responsible for high morbidity and mortality in the general population. ${ }^{9}$ Splenectomy seems to accelerate atherogenesis meaning a protective spleen effect ${ }^{8}$ and chow type can also significantly influence such mechanism. ${ }^{9}$ A dysbalanced diet, rich in hyperlipemic nutrients, as cholesterol, saturated fat or trans fat could worsen the dyslipidemic state during the postoperative period of total splenectomy. Knowledge of such complications has stimulated research focusing on the preservation of spleen function. One of the methods to preserve spleen tissue after splenectomy is by autotransplant of splenic sections. ${ }^{10}$ Some reports are available in the literature about clinical experience with spleen autotransplantation and experimental studies have been performed since the nineteenth century. Griffini and Tizzoni (1883) were the first to describe areas of spontaneous splenic regeneration in the peritoneum of dogs which had undergone to total splenectomy. ${ }^{11}$ The technical aspects concerning heterotopic splenic autotransplants have been widely reported in the literature. According to most authors, it is a simple procedure not associated with significant complications. Generally, an autotransplanted fragment of spleen undergoes almost complete necrosis and then regenerates to form a grossly normal spleen. ${ }^{12-14}$ Blood supply to the splenic tissue is the most important and determining factor for successful autotransplantation. Different sites and methods of autotransplantation have already been studied but it seems that the rich blood supply of the greater omentum leads to a better function than in other sites. ${ }^{10,14}$ A variety of animal models as well as studies in humans ratifies the regeneration of autotransplanted splenic tissue showing structural attributes similar to those of the normal spleen. ${ }^{12-14}$ Several clinical and experimental researches carried out on autogenous splenic implants have indicated the recovery of some spleen functions through indirect laboratory methods and scintigraphic techniques. Among the preserved functions are the ability to remove colloidal substances, altered erythrocytes, and corpuscular inclusions, such as Howell-Jolly, Heinz, and Pappenheimer from the bloodstream has been observed. Other elements that apparently return to normal are antibody production against pneumococci polysaccharides, and the immunoglobulin levels (notably IgM), complement, platelets, and lymphocytes. ${ }^{12,14}$ The effects of total splenectomy on the plasmatic lipids levels and consequently in atherosclerosis have been attested by several authors but only few studies considered the type of chow employed during the postoperative period. This study was aimed at evaluating the alterations on plasmatic lipids levels in rats submitted to total splenectomy isolated or combined with splenic autotransplant receiving a balanced standard diet during the postoperative period.

\section{Methods}

This study was approved by the Ethics Committee on Animal Research of the Biology Institute Roberto Alcântara Gomes, Rio de Janeiro State University - Brazil.

Animals - Thirty adult male Wistar rats weighing 240-270 g were randomly divided into three groups of 10 animals each: control (C) - sham-operated; total splenectomy (TS) - submitted to isolated total splenectomy; and splenic autotransplantation (SA) submitted to total splenectomy combined to spleen autotransplantation. All rats were housed in individual cages in rooms with controlled temperature and humidity and exposed to 12-hour day/night cycles. The rats were observed daily, during 12 weeks. At the end of the study, the animals were killed with an anesthetic overdose.

Surgical procedures - In the first day of the experiment, after a 12-h fast, the animals were submitted to general anesthesia with intraperitoneal sodium thiopental (50 mg/kg), abdominal trichotomy, antisepsis with iodopovidine, and placement of surgical fields. The surgical procedure was performed by supraumbilical midline laparotomy. In sham-operated group (C), the spleen was mobilized, brought to the wound surface, and 
subsequently replaced to its original position in the abdomen; total splenectomy (TS group) was performed with binding of the splenic vessels; in the group of animals submitted to splenic autotransplantation (SA), after total splenectomy the spleen was weighed and transversely cut into five segments, each about $2 \mathrm{~mm}$ thick. The splenic sections were implanted into the greater omentum using continuous 4-0 polyglycolic acid sutures. Stitches were introduced alternately into the omentum and splenic tissue to permit interposition of omental tissue between the splenic slices. Laparorrhaphy was carried out on two planes (peritoneal-aponeurotic plane and skin) using continuous 3-0 polyglecaprone 25 sutures. After recuperation of physical activity, the rats were replaced into their cages without alimentary restriction.

Blood analyses - After a 12-h fast the animals had blood samples collected immediately before the operation (D0) by cardiac puncture under anesthesia with intraperitoneal sodium thiopental. Additionally, the animals of all groups had blood samples collected after 6 and 12 weeks of the experiment, with previous12-h fat and also under anesthesia. In all blood samples the plasmatic levels of total cholesterol (TC), triglycerides (TG), high-density lipoprotein (HDL), low-density lipoprotein (LDL), very-low-density lipoprotein (VLDL), and glucose (GLUC), were analyzed.

Manipulation of chow and animal feeding - The animals were allowed to feed on commercial rat chow (Focus 1722 Roedores $^{\circledR}-$ Agroceres $^{\circledR}$ ) since the beginning of the experiment, with free access to water. Chow contents: sodium chloride, milled integral corn (8\% of brute protein), soy chaff (47\% of brute protein), wheat chaff (14\% of brute protein), bicalcic phosphate (19\% of phosphorus and $23 \%$ of calcium), calcium carbonate (39\% of calcium), DL-methionine, L-lysine, antioxidant addictive, and vitamin and mineral mix containing vitamin $A$, vitamin $E$, vitamin $K_{3}$, vitamin $B_{1}$, vitamin $B_{2}$, vitamin $\mathrm{B}_{6}$, vitamin $\mathrm{B}_{12}$, niacin, pantothenic acid, folic acid, biotin, iron, zinc, copper, iodine, manganese, selenium, and cobalt. Since the immediate postoperative period, all animals received manipulated standard rat chow based on the recommendations of the American Institute of Nutrition Rodents Diets (1993), ${ }^{15}$ appropriated for studies with experimental nutrition and adequate in micro and macronutrients for adult rodents that are not in reproduction phase (maintenance phase). Their intake of chow as well as their body weight was controlled weekly, always at the same day time.

Statistical analysis - Data regarding body weight variation and chow intake were analyzed using ANOVA (analysis of variance) and Tukey's post-test to compare pairs of groups. Data obtained from blood samples in different moments in the same group were analyzed by paired t-student test. The level of significance was set at pd”0.05 in all analyses. Statistical analyses were performed with the Graph Pad Prism $4^{\circledR}$ for Windows version 4.0, 2003 and the SAS Statistical Software Package ${ }^{\circledR}$ for Windows version 9.1, 2002-2003.

\section{Results}

In all groups there was loss of animals after cardiac puncture performed on the sixth week of the experiment ( $C$ -1 animal; TS -2 animals; SA -3 animals). In these groups analyses were performed with 9, 8, and 7 animals, respectively. During the study, initial weight (g), body weight gain (g), and chow consumption of the animals of the three groups (C, TS, and SA) did not significantly differ. (Table 1). Plasmatic levels of cholesterol of the animals in the control (C) and in the total splenectomy combined with splenic autotransplant (SA) groups remained similar in the three moments of evaluation (weeks 0, 6, and 12). Cholesterol levels in the splenectomized rats (TS) increased during the experiment, reaching values significantly higher in week 12 when compared to week 0 . (Table 2). A significant decrease was observed in HDL levels among weeks 6 and 12 in the animals of $C$ group and a significant increase of the same parameter occurred between weeks 0 and 6 among the rats of TS group. In spite of that such levels showed no difference between weeks 0 and 12 . However, in the rats of SA group it was observed a significant decrease in HDL levels between weeks 0 and 6; since then an increase of those levels occurred resulting in a significant increase of such parameter between weeks 6 and 12 and weeks 0 and 12. (Table 2). Even with significant variations in LDL levels between weeks 0 and 6 and weeks 6 and 12 in the animals of $\mathrm{C}$ group (reduction and increase, respectively), there was no difference in those levels in comparing weeks 0 and 12 . In TS group a significant reduction of LDL levels was observed until the sixth week (between weeks 0 and 6); however such parameter didn't significantly vary between weeks 0 and 12. LDL levels stayed unaffected in SA group during all the experiment. (Table 2). Triglycerides and VLDL levels behaved in the same way in all groups. In $\mathrm{C}$ group such values increased significantly until the sixth week, but from then there was a significant reduction, remaining, however, a significant increase from week 0 to 12 . In TS and SA groups triglycerides and VLDL levels increased significantly between weeks 0 and 6 and weeks 0 and 12 . (Table 2). In control group, glucose levels increased significantly between weeks 0 and 6 , but suffered significant reduction among weeks 6 and 12. In spite of those alterations there was no difference between weeks 0 and 12. In TS group, glucose levels increased significantly between weeks 0 and 6 and weeks 0 and 12. Such levels did not alter significantly in SA group. (Table 2). 
TABLE 1 - Descriptive analyses of body weight and chow intake in the various animal's groups.

\begin{tabular}{cccccc}
\hline Animal's groups & n (initial) & Initial weight (g) & n (final) & Final weight (g) & Chow intake (g) \\
\hline C & 10 & $261.28 \pm 6.28$ & 9 & $462.18 \pm 55.42$ & $1,495.73 \pm 169.27$ \\
TS & 10 & $254.21 \pm 7.77$ & 8 & $438.32 \pm 19.71$ & $1,396.45 \pm 146.07$ \\
SA & 10 & $253.26 \pm 8.15$ & 7 & $408.52 \pm 51.59$ & $1,317.55 \pm 200.62$ \\
\hline
\end{tabular}

$\mathrm{n}$ - number of animals.

Values are expressed as mean \pm standard deviation.

\section{Discussion}

TABLE 2 - Descriptive analysis of the variables observed in weeks 0,6 , and 12 of the experiment in each group of animals $-p$ values.

\begin{tabular}{llll}
\hline Variable & $\boldsymbol{C}$ & TS & $\boldsymbol{S A}$ \\
\hline TC (weeks) & & & \\
$\mathbf{0 - 6}$ & 0.5326 & 0.2193 & 0.3243 \\
$\mathbf{6 - 1 2}$ & 0.0821 & 0.0686 & 0.7180 \\
$\mathbf{0 - 1 2}$ & 0.1048 & $0.0387^{*}$ & 0.2841
\end{tabular}

HDL (weeks)

$\begin{array}{llll}\text { 0-6 } & 0.1292 & 0.0093^{*} & 0.0158^{*} \\ \text { 6-12 } & 0.0032^{*} & 0.6304 & <0.0001^{*} \\ \mathbf{0 - 1 2} & 0.3880 & 0.0835 & <0.0001^{*}\end{array}$

LDL (weeks)

$\begin{array}{llll}\mathbf{0 - 6} & <0.0001^{*} & 0.0095^{*} & 0.1198 \\ \mathbf{6 - 1 2} & 0.0046^{*} & 0.1018 & 0.4893 \\ \mathbf{0 - 1 2} & 0.3558 & 0.3053 & 0.1268\end{array}$

\section{VLDL (weeks)}

0-6

6-12

0-12

TG (weeks)

$\begin{array}{llll}\text { 0-6 } & <0.0001^{*} & 0.0001^{*} & 0.0014^{*} \\ \text { 6-12 } & 0.0039^{*} & 0.6082 & 0.1174 \\ \text { 0-12 } & 0.0004^{*} & 0.0031^{*} & 0.0038^{*}\end{array}$

GLUC (weeks)

\begin{tabular}{llll}
$\mathbf{0 - 6}$ & $0.0139 *$ & $0.0012^{*}$ & 0.9381 \\
$\mathbf{6 - 1 2}$ & $0.0295^{*}$ & 0.0698 & 0.6829 \\
$\mathbf{0 - 1 2}$ & 0.5680 & $0.0404^{*}$ & 0.7467 \\
\hline
\end{tabular}

* Significant difference; $\mathrm{C}$ - control group; TS - isolated total splenectomy; SA - total splenectomy combined with splenic autotransplantation.
Knowledge already spread concerning to the importance of attempting to preserve the spleen during elective or urgent surgical procedures, especially due to its relevant immunological function, has been challenging innumerous researchers in the search of mechanisms to maintain the organ function when the total splenectomy is inevitable. ${ }^{2,10,12-14}$ Several clinical and experimental studies are also demonstrating the important relationship of the spleen with the lipids metabolism, emphasizing the need of preserving its function. ${ }^{4-6,16}$ In this study an asplenic condition and an attempt for functional recovery of the spleen with autotransplant were created in rats since splenic autotransplantation seems to be the only alternative for preservation of splenic tissue after total splenectomy. ${ }^{10}$ Several animal models and studies in humans provide evidence in favor of the regeneration of the splenic autotransplanted tissue with similar structural characteristics to the normal spleen. ${ }^{10,12}$ However, there are still controversies with regard to the time that the spleen would take to completely regenerate in rats. Tavassoli et al (1973) observed that the functionality of the organ begins 5 weeks after the autotransplant. ${ }^{13}$ Iinuma et al (1992) evidenced it after 8 weeks, verifying that only after 16 weeks the regenerated splenic tissue turns indistinguishable from a normal spleen, ${ }^{14}$ which was also observed by Marques et al (2002). ${ }^{10}$ To monitor the evolution of the recovery of splenic function after splenic autotransplantation and consequently its action on the plasmatic lipids levels several biochemical variables were analyzed after 6 and 12 weeks of experiment. It was observed that only at 12 weeks occurred a significant increase, compared to the preoperative period, in the plasmatic levels of cholesterol of the animals submitted to isolated total splenectomy which confirms other authors' results, ${ }^{3,4,17,18}$ in opposition to an observation in rabbits fed with standard chow. ${ }^{16}$ Also in disagreement with other studies, ${ }^{4,17,18}$ LDL plasmatic levels did not alter in the animals submitted to isolated total splenectomy. Our results allowed the observation that splenic autotransplant can revert some alterations on plasmatic lipids levels. Blood levels of cholesterol and glucose, both elevated in the animals submitted to isolated total splenectomy (TS), didn't suffer alteration in the group of animals submitted to splenic autotransplantation (SA). Other studies also demonstrate that surgical procedures 
for preservation of the splenic function, like subtotal or partial splenectomy, are similarly able to revert the alterations of the lipids metabolism provoked by the absence of the spleen. ${ }^{17,18}$ Specifically related to glycemia, in the animals submitted to total splenectomy isolated (TS) or combined with splenic autotransplant (SA) it was observed that the spleen can also significantly influence such parameter, which seems having not been observed yet. Plasmatic levels of VLDL and triglycerides increased in all groups of animals until the end of the experiment, even in the control group in which no alteration was expected. In analyzing the composition of both rat chows, offered at preoperative and postoperative periods, it became evident their difference related to the nutrients source: while commercial chow used carbohydrates and proteins with a great content of fibers, chow preconized by AIN-93 contains only amide (and sacharosis) and casein (with contain no fibers) as sources for those macronutrients. This fact could probably justify the alteration on VLDL and triglycerides levels observed in all groups. Those lipidic components are largely influenced by the source and the amount of fibers of the diet, as already determined. ${ }^{9}$ It should be emphasized that even with values similarly elevated at week 12 of the experiment in all groups, in the group of animals submitted to isolated total splenectomy such values suffered a continuous elevation while in the control group and in the group with splenic autotransplants it was observed a continuous decrease of those values until the sixth week, as also verified by Lemos-Paulo et al (2005) during the postoperative period of total splenectomy in rats. ${ }^{17}$ Rat chow preconized by AIN-93, ${ }^{15}$ which is different from chow offered to the animals during the preoperative period, was utilized by all animals during the postoperative period with the intuit of controlling the composition of the diet. It was believed that a balanced chow should be more adequate to eliminate any alteration on the plasmatic lipids levels exclusively due to the diet. In some studies chow offered to the animals submitted to total splenectomy was modified, in an attempt to verify the influence of the diet on the plasmatic levels of lipids. ${ }^{6,16,17}$ Nevertheless, most authors have only increased the lipidic content in rat chow at the postoperative period, mainly by the addition of cholesterol, not permitting the observation of possible changes on lipids levels in ideal conditions of nutrients offering. Rabbits fed with chow containing high cholesterol levels present a significant increase in the plasmatic levels of lipids after total splenectomy, besides formation of ateroma plates evidenced by necropsia. ${ }^{16}$ Lemos-Paulo et al (2005) also found more significant alterations in the plasmatic lipids in splenectomized rats that received addition of cholesterol to the diet in comparison with animals receiving standard chow. ${ }^{17}$ However, it is already known that the addition of cholesterol by itself can modify the plasmatic lipids levels.

\section{Conclusion}

Our findings suggest that in rats fed with standard chow, isolated total splenectomy modify lipids metabolism and splenic autotransplantation is effective in restoring its control. Monitoring of the plasmatic levels of lipids in animals submitted to diverse surgical procedures over the spleen and fed with diets containing the same fat tenor at the postoperative period would be recommended. Further studies with different types of diets are also necessary to definitively establish the effect of such procedures on lipids metabolism.

\section{References}

1. Diamond LK. Splenectomy in childhood and the hazard of overwhelming infection. Pediatrics. 1969;43:886-9.

2. Miko I, Nemeth N, Sipka S Jr, Brath E, Peto K, Gulyas A, Furka I, Zhong R. Hemorheological follow-up after splenectomy and spleen autotransplantation in mice. Microsurgery. 2006;26:38-42.

3. King JH. Studies in the pathology of the spleen. Arch Intern Med. 1914;14:145-67.

4. Salomao-Paulo DN, Lazaro-da-Silva A. [The plasma lipids after total and partial splenectomy in dogs]. Rev Col Bras Cir. 2001;28:264-70.

5. Aviram M, Brook JG, Tatarsky I, Levy Y, Carter A. Increased low-density lipoprotein levels after splenectomy: a role for the spleen in cholesterol metabolism in myeloproliferative disorders. Am J Med Sci. 1986;291:25-8.

6. Fatouros M, Bourantas K, Bairaktari E, Elisaf M, Tsolas O, Cassioumis D. Role of the spleen in lipid metabolism. Br J Surg. 1995;82:1675-7.

7. Schmidt HH, Wagner S, Manns M. The spleen as a storage pool in lipid metabolism. Am J Gastroenterol. 1997; 92:1072-2.

8. Witztum JL. Splenic immunity and atherosclerosis: a glimpse into a novel paradigm? J Clin Invest. 2002;109:721-4.

9. Aro A, Jauhiainen M, Partanen R, Salminen I, Mutanen M. Stearic acid, trans fatty acids and dairy fat: effects on serum and lipoprotein lipids, apolipoproteins, lipoprotein (a), and lipid transfer proteins in healthy subjects. Am J Clin Nutr. 1997;65:1419-26.

10. Marques RG, Petroianu A, Coelho JM, Portela MC. Regeneration of splenic autotransplants. Ann Hematol. 2002;81:622-6.

11. Griffini L, Tizzoni G. Etude expérimentale sur la réproduction partielle de la rate. Arch Ital Biol.1883;4:303-6. 
12. Patel JM, Williams JS, Shmigel B, Hinshaw JR. Preservation of splenic function by autotransplantation of traumatized spleen in man. Surgery. 1981;90:683-8.

13. Tavassoli M, Ratzan RJ, Crosby WH. Studies on regeneration of heterotopic splenic autotransplants. Blood. 1973;41:701-9.

14. Iinuma H, Okinaga K, Sato S, Tomioka M, Matsumoto K. Optimal site and amount of splenic tissue for autotransplantation. J Surg Res. 1992;53:109-16.

15. Reeves, PG. Components of the AIN-93 diets as improvements in the AIN-76A diet. J Nutr. 1997;127:838S-841S.
16. Asai K, Kuzuya M, Naito M, Funaki C, Kuzuya F. Effects of splenectomy on serum lipids and experimental atherosclerosis. Angiology. 1988;39:497-504.

17. Lemos-Paulo IC, Salomao-Paulo DN, Lazaro-da-Silva A, Foletto RM, Colnago GL, Vargas PM. [Plasmatic lipids levels in rats after total splenectomy, simultaneous ligature of the splenic vessels, and subtotal splenectomy with inferior pole preservation]. Rev Col Bras Cir. 2005;32:229-36.

18. Petroianu A, Veloso DF, Costa GR, Alberti LR. [Effects of splenic surgeries on lipidogram of rats]. Rev Assoc Med Bras. 2006;52:56-9.

\section{Correspondence:}

Fernanda Correia Simões

Rua Marquês de Jacarepaguá 169, casa 03

22730-290 - Rio de Janeiro, RJ - Brazil

Phone:55-21-78300641; Fax:55-21-25876859

e-mail: fsimoesnut@hotmail.com
Conflict of interest: none Financial source: FAPERJ, Brasil 